\title{
LA TENSIÓN
}

IRRESUELTA ENTRE LA INDIVIDUALIDAD Y LA CIUDADANÍA

Juan Carlos Geneyro*

Decí, por Dios, ¿qué me has dao, que estoy tan cambiao, no sé más quién soy?

Enrique Santos Discépolo ${ }^{1}$

Si la modernidad se define como fe incondicional en el progreso, en la técnica, en la ciencia, en el desarrollo económico, entonces esta modernidad está muerta.

E. Morin ${ }^{2}$

\section{El desafío educativo de la modernidad}

Es un lugar común señalar como uno de los rasgos principales de la Modernidad la importancia que adquiere el individuo y el valor de su autonomía. Además, el conocimiento como emancipación catapulta el principio de la educación como un medio principal en el afianzamiento de la individualidad libre, crítica

* Profesor Titular de Filosofía y Teoría de la Educación, Universidad de Lanús, Argentina.

${ }^{1}$ Letras del tango Malevaje, 1928.

${ }^{2}$ En Los siete saberes necesarios para la educación del futuro, 2001, Buenos Aires, Nueva Visión, p. 69. 


\section{JUAN CARLOS GENEYRO}

y reflexiva, favorecedora de la creatividad cuando no del progreso y la competitividad, como es el caso de J. S. Mill. Pero, al mismo tiempo, desde ella se postula también a la educación como principal alternativa para la formación del ciudadano requerido por el Estado-Nación y/o por la propia sociedad; desde un proceso de socialización que lo pretende adaptado y conteste con legados culturales y normativos que sustentan una determinada identidad cívica nacional y/o social. ${ }^{3}$ Identidad que, así entendida, equivale a homogeneidad.

La tensión entre los principios o propósitos antes apuntados se resuelve en los distintos autores de la época según las tradiciones intelectuales a las que responden y que, según el caso, buscan enriquecer o trascender estableciendo otras nuevas. En la línea del primer principio, encontramos entre otros, autores tales como W. von Humboldt, J. S. Mill, F. Nietzsche, H. Bergson y J. Dewey.

W. von Humboldt asienta la ciudadanía sobre los pilares de la individualidad y la libertad. Sostiene que el hombre es un conglomerado de fuerzas y energías originales, que se ensamblan en un todo mediante el ejercicio de su individualidad en libertad:

El verdadero fin del hombre... es la más elevada y proporcionada formación posible de sus fuerzas como un todo. Y para esta formación, la condición primordial e inexcusable es la libertad. Pero, además de la libertad, el desarrollo de las fuerzas humanas exige otra condición... la variedad de las situaciones. Incluso el hombre más libre y más independiente, puesto en una situación de uniformidad, se forma menos. ${ }^{4}$

En esa perspectiva, rechaza la educación pública como acción del Estado, dado que ésta, por tener necesariamente unidad de organización, produciría una cierta uniformidad en los efectos de aquélla. Más aún, la educación de los individuos concretos, con independencia de

${ }^{3}$ La disyuntiva entre lo nacional y lo social es procedente según sea el sentido que se otorgue al término nación.

${ }^{4}$ Humboldt, W. Los límites de la acción del Estado, 1998, España, Tecnos, p. 14. 
INDIVIDUALIDAD Y CIUDADANÍA

las características de la organización estatal existente y las condiciones sociales, ${ }^{5}$ permitirá que puedan -ya como ciudadanos- analizar críticamente y mejorar dicha organización política. Si, por el contrario, la educación para la niñez y la juventud estuviera a cargo del Estado, dirigida al súbdito o al ciudadano, la conformidad resultante no sólo limitaría esa crítica, sino que empobrecería también el carácter moral de éstos y la propia autonomía individual. Sobre este particular, transcribo:

Casi el único medio de que dispone el Estado para adoctrinar a los ciudadanos consiste en formular lo que él cree mejor -en cierto modo, el resultado de sus investigaciones-, en imponerlo directamente por medio de una ley o, indirectamente, a través de cualquier institución obligatoria para los ciudadanos...; pero, sea cualquiera el método que siga, siempre se alejará demasiado del mejor camino para enseñar. Este camino consiste...en exponer todas las posibles soluciones del problema, limitándose a preparar al hombre para que elija por sí mismo la que crea más adecuada; o, mejor aún, en hacer que él mismo la ‘descubra' desde la correspondiente exposición de todos los obstáculos. ${ }^{6}$

Al cuestionar la excesiva actuación del Estado, concluye que conduce a la mediocridad y pereza individual y cívica. Cabe subrayar, además, su crítica a la búsqueda de la felicidad orientada por el interés de resultados materiales, antes que la de la virtud moral. La expresión de la individualidad, en tanto conglomerado original de energías, indica que la actividad en sí misma, entendida como arte, deprecia su carácter formativo si sólo es concebida como medio desde el interés preocupado por el resultado material, en desmedro del cultivo de la propia interioridad espiritual. Por último, sorprende su tesis sobre los educado-

${ }^{5}$ Hay en este punto una clara reminiscencia de la propuesta educativa del Emilio de J. Rousseau.

${ }^{6}$ W. Humboldt, op. cit., p.25. 
res; sostiene que son mejores cuando su suerte depende del éxito de su trabajo que cuando depende -como funcionario o empleado público-de la promoción que han de esperar del Estado. Esta tesis, extendida a la propia educación, tiene partidarios en la actualidad, particularmente entre quienes buscan argumentos para que el Estado reduzca sus 'déficits' mediante la reducción del 'gasto educativo'.

En el caso de J. S. Mill, su ensayo sobre la libertad apela a la originalidad como atributo del individuo para su elección y actuación en pos de la felicidad; destaca su preferencia por lo excéntrico antes que caer en la rutina costumbrista.

Mill, en su conocido trabajo Sobre la libertad, ${ }^{7}$ apunta que seguir la costumbre como costumbre no educa ni desarrolla las cualidades propias y distintivas del ser humano. El despotismo de la opinión y de la costumbre, ejercita sólo la imitación y obstaculiza el enriquecimiento de las mismas. Mientras que las cualidades a desarrollar por cada individuo -desde la construcción y ejercicio de su autonomía- suponen las facultades de la observación y el análisis reflexivo, competencias para acceder y utilizar información requeridas en la deliberación, el discernimiento para la toma de decisiones, así como de firmeza y autodominio para sostener las mismas. De ahí su sentencia: "El que hace una cosa cualquiera porque ésa es la costumbre, no hace elección alguna”. Apelando a Humboldt, destaca el valor de la originalidad, que se nutre de la diversidad múltiple de la naturaleza humana y del vigor individual, para el desarrollo de las fuerzas interiores que cada individuo posee y hacen de él 'una cosa viva'. ${ }^{\circ}$

${ }^{7}$ J. S. Mill, Sobre la libertad, 1981, 3a., Madrid, Alianza. Prólogo de I. Berlin. Ver especialmente el punto 3, De la individualidad como uno de los elementos del bienestar; p. 125 s. También J. Dewey critica la "producción en masa de la opinión” de los medios de comunicación. Este tema puede consultarse en: Libertad y cultura, 1965, México, Uteha.

${ }^{8}$ No obstante, hay que apuntar que sobre el papel de la opinión pública J. S .Mill manifiesta una cierta ambigüedad, porque también le otorga un papel de moderación o de juicio moral respecto a las posibles consecuencias del accionar de egoísmos exacerbados. 
INDIVIDUALIDAD Y CIUDADANÍA

Coincide con W. von Humboldt, pero con otros argumentos, en cuanto que el Estado debe reducir al mínimo su actuación en nombre del bienestar de sus ciudadanos (incluida la educación; excepto que ella no esté provista a niños y jóvenes por irresponsabilidad paterna). En la visión utilitarista de J. Mill, se sabe, la naturaleza humana es de por sí egoísta. En libertad, cada quien al actuar buscará placer o evitar dolor según sea su particular preferencia. Además, el Estado es susceptible de sospecha o, más bien, quienes desde él ejercen poder, porque en tanto hombres y por dicha naturaleza pueden obrar en búsqueda de su propio beneficio particular (el interés privado encubierto, apariencia -en el sentido nietzscheano- de interés público) y no del bienestar general. No puedo aquí dejar de referir estas prevenciones de Mill a nuestra actualidad, pletórica de ejemplos de quienes en el ejercicio del poder público han obtenido buenos resultados para sus intereses privados. Creo que el propio Weber coincidiría en que una cosa es vivir de la política y otra muy distinta enriquecerse mediante ella.

Mill establecía una estrecha relación entre educación y progreso, dado que buena parte de la caracterización que hace de éste remite a aquélla de una u otra manera: el desarrollo de las ciencias y de las técnicas que aseguran el mejor aprovechamiento de los recursos naturales; las posibilidades de la asociación, la cooperación y la competitividad para el desarrollo económico; la necesidad de la educación para las clases trabajadoras con el fin de lograr relaciones más paritarias con los empresarios en cuanto a la organización y resultados de las actividades productivas; el propio papel de la mujer en dichas actividades; etc. Digamos, para otorgar sentido a las palabras de Discépolo y Morin que utilizo en el encabezado de este artículo, que si la Modernidad fuese mujer, estaría prendado de ella.

Nietzsche, por su parte, en el tránsito hacia el surgimiento del hombre nuevo, encuentra en la inocencia y el olvido (respecto de los legados modernos) las condiciones fundacionales de otra moral. Como se verá, es un acérrimo crítico de las costumbres y opiniones que opacan la original individualidad. 
JUAN CARLOS GENEYRO

Releyendo su trabajo, Schopenhauer como educador (Tercera consideración intempestiva), ${ }^{9}$ se pueden confirmar las inquietudes de aquél respecto de temas relacionados con la educación y la moral, siempre manifiestas en sus análisis críticos sobre los perfiles políticos, sociales y científicos, culturales en general, que mostraba la moderna sociedad europea del siglo XIX y particularmente Alemania.

Como señala Luis Fernando Moreno, en el prólogo de la edición de la obra antes citada:

Las consideraciones intempestivas eran una serie de escritos de corta extensión que...pretendían ser combativos e ir a contracorriente de las opiniones que pasaban por válidas y comunes en la época...verdaderos alegatos contra los absurdos y el filisteísmo que parecían reinar en la política, la sociedad, las instituciones y la cultura... ${ }^{10}$

Nietzsche las concebía, según sus propias palabras, como un buen arma para 'golpear a la gente en su cabeza'; no golpes físicos, claro está, pero no por ello menos contundentes y destinadas a una opinión pública, que por ser tal, albergaba o escondía 'las perezas privadas'. Se hace necesario aquí indagar en el sentido otorgado por el autor a las perezas privadas. Así como J. Dewey sostiene que 'lo primitivo en el hombre es lo adquirido’, para apuntar que la rutina y los hábitos incorporados no sujetos a la reflexión y a la imaginación creativa convergen para solo vivir de los legados, como si fueran una renta dejada por nuestros antepasados para que vivamos cómodamente, según Nietzsche el cobijamiento en la opinión pública permite eludir el desafío que conlleva para el hombre asumirse como milagro irrepetible; oportunidad única e insustituible de realización. Pero, al mismo tiempo, esta posibilidad le arroja a cada quien el desafío de

${ }^{9}$ F. Nietzsche, Schopenhauer como educador (Tercera consideración intempestiva), 2001, 2a., Madrid, Valdemar. Prólogo de Luis Fernando Moreno Claros.

${ }^{10}$ Ibid., p. 20. 
INDIVIDUALIDAD Y CIUDADANÍA

liberarse de la cadena de las opiniones, a dejar de pensar y actuar como lo hacen los demás.

No puedo menos que llamar la atención sobre la coincidencia que en este punto presenta también con J. S. Mill, con quien comparte además su recelo acerca del papel del Estado, aunque no por ello se siga que hay entre ambos visiones similares sobre cuestiones tales como el progreso, la ciencia, los empresarios, como se verá a continuación. También en el entorno de su época, (podemos interrogarnos sobre la nuestra) Nietzsche encuentra que no hay hombres vivos sino “apariencias humanas con opinión pública”.

En esta Consideración Intempestiva, el autor analiza las manifestaciones de cuatro tipos de egoísmos:

- el egoísmo de los propietarios;

- $\quad$ el egoísmo del Estado;

- el egoísmo de los simuladores y menesterosos de la forma, y

- el egoísmo de los eruditos.

En el análisis del primero, puede encontrarse la más apretada síntesis del pensamiento nietzscheano en cuanto a sus críticas de una educación para el éxito, utilitaria, destinada a confirmar el supuesto de una alianza natural entre inteligencia y haber que, peor aún, se presenta incluso como una necesidad moral. Dicho supuesto descansa en la siguiente lógica, parafraseando al autor: a más cultura y educación posibles, más necesidades posibles; consecuentemente, más producción y de ella, se sigue, más ganancias y felicidad (aquí es obvio su desencuentro con Mill).

Sin embargo, señala que más cultura es, en verdad, sólo la cultura necesaria para el interés utilitario; una instrucción rápida del individuo para que prontamente sea alguien que gana dinero. El siguiente párrafo ilustra su crítica sobre esa concepción utilitaria de la educación, de esa educación de hombres corrientes y que es al mismo tiempo un temprano cuestionamiento a la luego denominada teoría del capital humano: 
JUAN CARLOS GENEYRO

Sus partidarios definirían la educación como el conocimiento con el que uno se torna tempestivo con respecto de sus necesidades y la satisfacción de éstas; con el que uno, a la vez, se adueña y dispone lo mejor posible de todos los medios y vías para ganar dinero con facilidad. Formar el mayor número de hombres 'corrientes' -en el sentido en que se aplica 'corriente' a una moneda-, éste sería el propósito..., un pueblo será tanto más dichoso cuanto más hombres ‘corrientes’ posea. ${ }^{11}$

Por otra parte, al analizar el egoísmo del Estado aborda el tema de la socialización y el sentido que aquél le imprime a la expansión generalizada de la educación entre sus ciudadanos. No se dirige, argumenta, a liberar y expandir las energías individuales; la originalidad y potencialidad creativa de cada quien. Persigue su aprovechamiento por las instituciones establecidas y esa es la medida de la expansión de dichas energías. Lejos está Nietzsche de suscribir que este tipo de educación sustente una efectiva autonomía. ${ }^{12}$ Pueden apreciarse aquí, como también en cuanto a sus críticas de la educación del hombre corriente, sus coincidencias con W. Humboldt.

56 Quiero solamente, respecto a H. Bergson, señalar que hay en él siempre un llamado a la creatividad que gesta la intuición, que por sí sola la inteligencia no favorece. Curiosamente, la intuición pierde importancia e interés en múltiples propuestas de la pedagogía moderna como facultad o atributo a ser considerado por la educación; Bergson es uno de los pocos autores que la recupera como ejercicio y experiencia necesarios para la vida humana; es la manifestación del impulso vital.

En lo que concierne a J. Dewey respecto de los temas planteados, además de las fuentes ya citadas, remito al lector a un artículo mío

11 Ibid., p. 112.

12 Para el tema de la autonomía en Nietzsche, puede consultarse de M. Hopenhayn, Después del Nihilismo. De Nietzsche a Foucault, 1997, Santiago de Chile, Andrés Bello. Este autor apunta también coincidencias entre J. S. Mill y Nietzsche. 


\section{INDIVIDUALIDAD Y CIUDADANÍA}

publicado en esta misma Revista. ${ }^{13}$ No obstante, quiero apuntar que de este filósofo, en su ideal de la democracia, sorprende su tesis de que ella debe concebirse como una aristocracia universalizada, en cuanto que así entendida posibilita que cada individualidad pueda realizarse en su particular distinción.

En la óptica de la segunda perspectiva sobre la educación, nos aparece el J. Rousseau del Contrato Social, o del Ensayo sobre el gobierno de Polonia; donde el soberano o el Estado son los principales actores en la socialización de los futuros ciudadanos. ${ }^{14}$ La fuerte afirmación del Contrato Social, de que el Estado como mandatario del Soberano debe forzar al individuo a que sea libre según la decisión de este último (de su voluntad general), ilustra nuestra elección del autor. Sin embargo, hay que decir que la tensión entre la individualidad y la ciudadanía encarna en el pensamiento roussoniano en su perspectiva humanista. ${ }^{15}$ Desde ésta, concibe a la educación de Emilio orientada a evitar que se subordine a las opiniones de otros, asentadas en apreciaciones arbitrarias que no tienen otra ley que la moda o los prejuicios.

Sin duda, un claro representante de esta perspectiva es A. Comte quien, como he apuntado en otros trabajos, ${ }^{16}$ ha aportado quizás el legado con mayor incidencia en las propuestas educativas de la segunda mitad del siglo XIX en no pocos de los Estados Nacionales latinoamericanos. Comte demanda un nuevo orden social y ello requiere la cons-

13 J.C. Geneyro, “Educación y democracia: aportes de John Dewey”, en Estudios, n 39-40, (Décimo Aniversario), Invierno 94-Primavera 95, México, p. 77-98.

${ }^{14}$ Ver S. Todorov, Frágil felicidad (Un ensayo sobre Rousseau), 1987, Barcelona, Gedisa. Rousseau plantea la intervención directa del Estado en la educación en su análisis de la sociedad polaca, que Todorov analiza, p. 37 s.

${ }^{15}$ Un estudio pormenorizado sobre la cuestión se encuentra en S. Todorov, El Jardín imperfecto. Luces y sombras del pensamiento humanista, 1999, Barcelona, Paidós-Ibérica.

${ }^{16}$ Ver, por ejemplo, "Los fundamentos axiológicos de la ciencia social y sus implicaciones educativas: A. Comte, E. Durkheim y T. Parsons”, en Pedagogía, n² 2, 1984, México, Universidad Pedagógica Nacional. 


\section{JUAN CARLOS GENEYRO}

trucción de un fondo común de verdades por parte de los científicos, destinado a generar un consenso -más bien un mandato imperativoentre los ciudadanos para superar el caos y la anarquía que advierte en la Francia posrevolucionaria; fondo de verdades que deberá ser trasmitido por la educación.

En E. Durkheim encontramos la tensión apuntada en varios de sus escritos. Si bien destaca su concepción del hombre en tanto fuente autónoma de acción, así como en cuanto que el individualismo combate la servidumbre intelectual y advierte que el individuo es la realidad moral que debe servir de norma tanto a la conducta pública como a la conducta privada, al mismo tiempo, en su clásica definición de la educación se manifiesta el énfasis de la socialización (la educación homogénea), con un claro protagonismo del Estado en el ejercicio y direccionalidad de ese proceso. ${ }^{17}$

Al pasar, recordemos que el mismo S. Freud estuvo preocupado por cuestiones similares, resolviendo la tensión a favor de un proceso de socialización que garantizara la internalización de un marco normativo en los individuos para preservar la convivencia social. ${ }^{18}$

En los autores citados dentro de la primera óptica, hay una relativa coincidencia en cuanto a la inconveniencia de que la costumbre adoptada y ejercida desde el hábito irreflexivo sea principal fuente de referencia para la actividad de los individuos. En el mismo tenor, puede constatarse una prevención hacia la ‘opinión pública’ como articuladora o sustento de actitudes y acciones individuales. Algunos de ellos (particularmente J. S. Mill, F. Nietzsche y J. Dewey) expresan sus reticencias a que la doxa colectiva se constituya en un referente obligado para el individuo. Antes bien, ella conduciría a dependencias ilegítimas para un proyecto de individualidad libre y creativa. ${ }^{19}$

${ }^{17}$ Para advertir en E. Durkheim la tensión referida, ver J. C. Geneyro, La democracia inquieta: E. Durkheim y J.Dewey, 1991, Barcelona, Anthropos.

${ }^{18}$ Un pormenorizado estudio sobre el tema se encuentra en C. Millot, Freud antipedagogo, 1982, España, Paidós.

${ }^{19}$ El tema de la creatividad en el campo educativo, particularmente en algunas profesiones, entraña problemas y desafíos de difícil resolución, si 
INDIVIDUALIDAD Y CIUDADANÍA

Del mismo modo, desde la segunda óptica, durante la segunda mitad del siglo XIX en países como México y Argentina, las dirigencias que se proponen instituir el Estado-Nación para superar las luchas internas entre conservadores y liberales o entre unitarios y federales según el caso, imprimen a la educación estatal un fuerte carácter socializador para el nuevo ‘orden social’. Formación científica básica, formación cívica y laica, son componentes principales del ideario de esa socialización educativa estatal; el maestro será el apóstol de esa misión. Cabe señalar que el imaginario educativo devenido del afianzamiento del Estado-Nación en la modernidad pervive aún contradictoriamente con el tan mentado proceso de globalización. ${ }^{20}$

\section{Algunas inquietudes sobre la política y la educación ante la muerte de la modernidad.}

El recorrido por las visiones de los autores mencionados respecto a los temas planteados anteriormente, ofrece pistas para interrogarnos sobre cuestiones que nos preocupan en la actualidad. Entre ellas: la producción en masa de la opinión, como diría J. Dewey, a cargo actualmente del llamado cuarto poder y de la comunicación mediática, fenómeno que también concurre a empobrecer nuestras propias identidades culturales y nuestros propios lenguajes, a empobrecer por ende nuestras propias autonomías. También, paradójicamente, se verifica la ausencia de un fondo común de verdades que supere la fragmentación social y la incertidumbre que agobia todo intento creativo para mejorar el estado de nuestras democracias.

se aspira a una propuesta normativa para su logro. Véanse, por ejemplo, algunas consideraciones que planteo en mi artículo "Educación y creatividad”, en Educación Artística, mayo-junio de 1994, México.

${ }^{20}$ Sobre este punto, puede consultarse de J. Gimeno Sacristán, Políticas y prácticas culturales en las escuelas: los abismos de la etapa posmoderna, 1997, España, Universidad de Valencia, http://www2.uca.es/HEURESIS/ heuresis97/indi.html. 


\section{JUAN CARLOS GENEYRO}

Cuestionarnos, además, la centralidad del mercado y la fuerza centrífuga que genera para el sentido de la educación, particularmente de la educación superior, en desmedro muchas veces de actividades y fines relacionados con la formación cultural, la solidaridad y el compromiso social; la influencia del 'curriculum oculto' -en verdad 'develado' si se lo refiere-en términos de hábitos y actitudes que exacerban el interés utilitario de ganar dinero. Preguntarnos sobre la validez y pertinencia de la creciente preponderancia de opiniones despreocupadas de los fines no utilitarios de la educación, que apuntan a concebir y realizar una democracia más cabal. ${ }^{21}$

Plantearnos, a fin de cuentas, si las deficiencias de la política para satisfacer la representatividad social sólo se responden desde el diagnóstico de la crisis de aquélla y de sus costos para el gasto social, tal como sostienen ciertas opiniones públicas ¿Acaso la crisis de la política no es también una crisis moral? Vale aquí transcribir unas reflexiones de Nietzsche:

¿Dónde están en realidad para todos nosotros, eruditos y no eruditos, grandes y pequeños, nuestros modelos y celebridades morales entre nuestros contemporáneos, la encarnación visible de toda creatividad moral en nuestro tiempo? ¿Adónde ha ido a parar...toda aquella reflexión sobre cuestiones morales que en cualquier época ocupó la atención de toda sociedad noble y desarrollada? Hoy no existen ni celebridades ni reflexión alguna..., no hacemos sino consumir el capital de moralidad que acumularon nuestros predecesores y que nosotros no sabemos aumentar sino sólo dilapidar... Se ha llegado a un punto en el

${ }^{21}$ Para analizar las relaciones entre educación y democracia, desde la óptica del liberalismo igualitario, ver el artículo de R. Vázquez, "Hacia una educación igualitaria y democrática”, en Estudios, n 39-40, México, p. 141-68 También en este artículo de R. Vázquez pueden encontrarse análisis respecto de la autonomía. Si se sigue la concepción de M. Bovero, la educación es una 'precondición necesaria’ para ese cometido. Ver “Democracia y derechos fundamentales”, en Isonomía, n 16, abril 2002, México, p. 21-38. 


\section{INDIVIDUALIDAD Y CIUDADANÍA}

que tanto nuestras escuelas como nuestros maestros prescinden simplemente de una educación moral o se contentan tan sólo con el mero formalismo; y 'virtud' es una palabra acerca de la cual ni maestros ni escolares se arriesgan a pensar algo, una palabra pasada de moda de la que es mejor burlarse; y malo cuando no se hace burla de ella, pues entonces se es hipócrita. ${ }^{22}$

El ‘pensamiento único’, de la mano con el proceso de globalización, han sido generadores de la producción en masa de la opinión en los últimos tiempos. El sentido de esa producción impacta con particular resonancia en políticas y análisis económicos de organismos y corporaciones multinacionales o trasnacionales, en los que el mercado se instituye como ámbito deseado o necesario, según sea la posición e intereses de quienes los formulan, los representan, los ejecutan o los experimentan. La educación no queda exenta de dicha resonancia; en parte porque el propio Estado-Nación es más auditor que interlocutor de esas agencias, en parte porque la opinión pública la concibe como vía para la no exclusión del mercado. Es obvio que no es erróneo concebir a la educación de ese modo. El tema es otro cuando la educación tiene como principal -cuando no único- cometido ese fin, en desmedro de la consecución de otros bienes sociales, morales y culturales.

No sé qué tanto en la actualidad puede mantenerse que la educación sesgada por el interés y las demandas del mercado conduce seguramente al éxito individual y, concomitantemente, a la prosperidad social. No pocas veces se registran frustraciones individuales, apenas disimuladas por condiciones precarias de inserción laboral, cuando no imaginarios sociales que opacan con pesadumbre las tesis optimistas sobre la educación como canal de movilidad social.

Si, como algunos analistas sostienen, ${ }^{23}$ la globalización ha socavado las bases del Estado-Nación en cuanto a su autonomía y protagonismo

${ }^{22}$ F. Nietzsche, op. cit., p. 46-7.

${ }^{23}$ Ver D. García Delgado, Estado-Nación y Globalización, 1998, Buenos Aires, Planeta. También, J. C. Tedesco, Educar en la sociedad del conocimiento, 2000, México, FCE. 


\section{JUAN CARLOS GENEYRO}

para formular y aplicar políticas públicas que garanticen calidad de vida a sus ciudadanos -entre ellas las referidas a la educación- cabe interrogarse entonces sobre la diluida identidad y ejercicio de la ciudadanía; también sobre la pérdida de autonomía de los propios individuos para elaborar y realizar sus proyectos de vida.

Conviene señalar aquí, apelando a Castoriadis, que la autonomía individual no puede ser resuelta si no se la plantea como un desafío político de y para la democracia:

Llamo autónoma a una sociedad que no sólo sabe explícitamente que ha creado sus leyes, sino que se ha instituido a fin de liberar su imaginario radical y de poder alterar sus instituciones por intermedio de su propia actividad colectiva, reflexiva y deliberativa. Y llamo política a la actividad lúcida que tiene por objeto la institución de una sociedad autónoma y las decisiones relativas a las empresas colectivas... Es inmediatamente evidente que el proyecto de una sociedad autónoma pierde todo sentido si no es a la vez el proyecto que apunta a hacer surgir individuos autónomos $-\mathrm{y}$ a la inversa. ${ }^{24}$

Paradójicamente, la teoría del capital humano le ha otorgado más vigencia a la educación como consumo. Porque así suele ser vista por cierto tipo de evaluaciones relativas al funcionamiento del sistema educativo que indican sobre fenómenos tales como deserción (abandono o, mejor dicho, exclusión), desgranamiento, repetición, irregularidad en las trayectorias de los alumnos y escaso egreso de los niveles superiores, cuando no una falta de correspondencia respecto de los requerimientos del mercado, etc. A decir de W. von Humboldt, una particular preocupación por los resultados del sistema que deprecia el valor del proceso formativo mismo; y digo que relega (u olvida) el análisis y resolución de las condiciones sociales que inciden significativamente en ese tipo de resultados.

${ }^{24}$ C. Castoriadis, El mundo Fragmentado, 1990, Buenos Aires, Altamira, p. 106. 


\section{INDIVIDUALIDAD Y CIUDADANÍA}

Las condiciones de vida actuales para muchos ciudadanos, particularmente en algunos países latinoamericanos, y su impacto negativo sobre los trayectos y rendimientos educativos, sugieren que la educación como servicio público (que no queda restringido a lo estatal) debe ser acompañada por otras condiciones y bienes que hagan más sustentable la inversión social en educación. ${ }^{25}$

Conviene apuntar aquí que Castoriadis, al interpretar la afirmación de Freud sobre las tres profesiones imposibles (el psicoanálisis, la pedagogía y la política) se interroga sobre la posibilidad de que una propuesta pedagógica genere por sí sola autonomía. Al respecto señala:

...la imposibilidad también parece consistir, particularmente en el caso de la pedagogía, en la tentativa de volver autónomos a hombres y mujeres dentro del marco de una sociedad heterónoma y, yendo aún más lejos en este enigma aparentemente insoluble, ayudar a los seres humanos a acceder a la autonomía a la vez que - o a pesar de que - ellos absorben e interiorizan las instituciones existentes. ${ }^{26}$

El dilema, para Castoriadis, puede resolverse desde la política, desde un relanzamiento de la democracia. Se establece así una íntima relación

${ }^{25}$ En la sección dedicada a la Universidad, el diario Página 12, editado en Buenos Aires, Argentina, del día 20 de junio de 2002, señala las preocupaciones y acciones de algunas universidades nacionales para paliar la escasa o deficiente alimentación de buena parte de sus estudiantes. Al mismo tiempo, ante un índice de desempleo que ronda el 23\%, los jóvenes (hasta una edad de 29 años) declaran que prefieren seguir dentro de la universidad, como alternativa para complementar sus estudios de grado con alguna credencial de posgrado. En nuestros países latinoamericanos se registra una tendencia a concebir el posgrado como una mejor condición de competitividad personal en el mercado. En países donde la calidad de vida está más garantizada, el posgrado se orienta más al estudio y a la investigación de cuestiones disciplinarias o estratégicas para el desarrollo. Está mucho menos mediado por la perentoriedad de hacerse un lugar en el mercado.

${ }^{26}$ C. Castoriadis, op. cit., p. 99-111. 


\section{JUAN CARLOS GENEYRO}

entre política y pedagogía, que me hace recordar las tesis de A. Gramsci. Y agrego que para este pensador, cultura remite al adueñamiento del propio yo interior.

Por ello, hay que retomar el sentido de la educación como consumo; consumo necesario para vivir como individuo y como ciudadano todavía esperanzado, decidido y activo para que advengan condiciones que permitan a cada quien constituirse en actor protagónico de su respectivo proyecto de vida y para formar parte del elenco preocupado y ocupado en una mejor realización de la democracia que quiere vivirse. Porque, no siendo así, y ante la muerte de la modernidad según Morin, ¿no es cuestionable acaso el afán socializador del Estado y de otras instituciones sobre los individuos para constituirlos ciudadanos, si el destino manifiesto de muchos es la marginación, cuando no la exclusión social? ¿Cuál individualidad y cuál autonomía cabe esperar si no en esta llamada “crisis del modelo”?

Desde el análisis de Nietzsche sobre los riesgos que debe afrontar el hombre para constituir su individualidad y su autonomía, irrumpe en la desesperanza del duelo por la muerte de la modernidad su sentencia: "Vivir, en general, quiere decir estar en peligro". Cabe esperar que desde la ética, la política y la pedagogía, con energía, pasión y creatividad, surjan respuestas para atemperar el peligro y construir la utopía de otra modernidad. 